\title{
The Main Directions of Cost Reduction and Increasing Effectiveness in Cotton Production
}

\section{Alojonovich RR*}

Agricultural Research Institute, Toshkent, Uzbekistan

\begin{abstract}
Increasing efficiency by reducing costs plays an important role in agricultural production. In particular, to increase profit through reducing the cost of cotton is very important to raise productivity. Therefore, it is necessary to learn and study of the issues of increasing cotton production and effective cost reduction in the modernizing economic conditions of the agriculture especially, in the cotton sector. Reducing production costs and product net cost reduction is one of the most important requirements the of market system. The development of production, the level of its organization, the technical development and technology is closely connected to reducing the production cost. The net cost of product reflects the company's economic stability and the ability to operate in any form of property.
\end{abstract}

Keywords: Cotton; Resources; Technologies; Cost; Network functions; Social; Economic; Financial; Financial resources; Agricultural machinery; Resource savings

\section{Introduction}

The issues of development of the cotton sector and increasing its effectiveness need to consider together with the cotton processing sector. Before passing on the cost reduction opportunities it is needed to separate the cost factors and the sources from each other. Agricultural farms with when we speak about efficient means we understand achieving economies of resources and economic elements and costing items. Cutting of production costs, and reducing the net cost and increasing labour productivity in the sector is an important factor.

\section{Brief Literature Survey}

When we say labour productivity, we must understand the used machinery and technology for producing the production of one type of product and the amount of time spent [1]. The main source in reducing the production costs at agricultural product producing enterprises is saving expenses. For material cost savings there must be used cost savings out of raw materials and other products, efficient use of materials, storage and transport of raw materials and preventing waste and the quality and there must be carry out such work in continuously improving the skills of farm workers.

During the modernization of the economy of the country great attention is paid to support enterprises of the real sector. In supporting the real sector there must be done work in the following areas as reducing the cost of the product, providing tax incentives for exporters and supporting by providing bank credits for expansion of production areas. Among these areas the one that is closely depends on the enterprises is reducing the cost. These directions are shown in the book of President Islam Karimov "The global financial and economic crisis, ways and measures to overcome it" (Figure 1) [2].

Cotton output growth in cotton growing and its cost being comparatively lower will lead to saving a large amount of resources. Agricultural labour resources will be reallocated. There will appear an opportunity to send freed labour resources to different branches of industry which don't demand deep skills and knowledge. As a result, the quality level of labour resources will be improved, and that is the greatest wealth [3]. A number of Uzbek economist scientists devoted their research the problem of use of resource saving processes. In particular A. Abdiev states about resource expenditures in cotton growing that "Annually we are increasing the amount of mineral fertilizer in cotton growing but it doesn't ensure the productivity of cotton, because in practice we don't use them effectively [4]. That is why we should develop new technologies of use of mineral fertilizer". Economist scientist O. Shermatov says: "The technology should be considered in complex. Disorder in one process causes the decreasing of efficiency of resource use in all following processes. On the contrary, properly application of technological processes, use of new technologies provides increasing of amount of produced products with the same resource use" [5].

\section{Methodology}

Research for the implementation of the process of economic and statistical analysis, monograph abstract thinking, observation methods used.

\section{Main Trends in Reducing Prime Cost}

In cotton production, and organizing their processing along with theses directions there can be used more effective directions. These areas are:

1. Another important aspect in the system of reducing production costs is lowering labour value of product. Until the cotton fibre, which considered to be the main product of cotton production is ready, there would be used the labour value for cotton seed preparation for sowing, land preparation works wide range of labour of operating personnel carriers, maintenance personnel controllers and cotton processing enterprises employees' labour costs. By decreasing labour costs of production there can be reduced labour intensity. As a result, product cost will be lowered (Figure 2).

*Corresponding author: Alojonovich RR, Agricultural Research Institute, Toshkent Uzbekistan, Tel: +99893-498-96-84; E-mail: r.rashidov84@mail.ru

Received October 09, 2017; Accepted October 19, 2017; Published October 26, 2017

Citation: Alojonovich RR (2017) The Main Directions of Cost Reduction and Increasing Effectiveness in Cotton Production. Agrotechnology 6: 168. doi: 10.4172/2168 9881.1000168

Copyright: $\odot 2017$ Alojonovich RR. This is an open-access article distributed under the terms of the Creative Commons Attribution License, which permits unrestricted use, distribution, and reproduction in any medium, provided the original author and source are credited. 


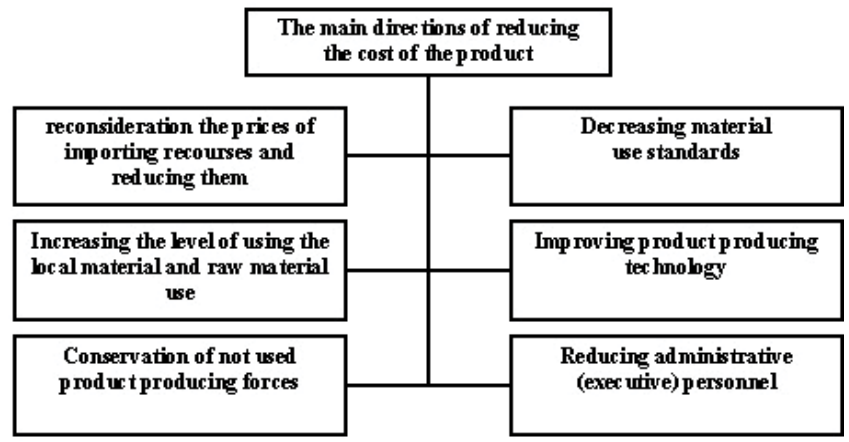

Figure 1: The main directions of reducing the cost of the product.

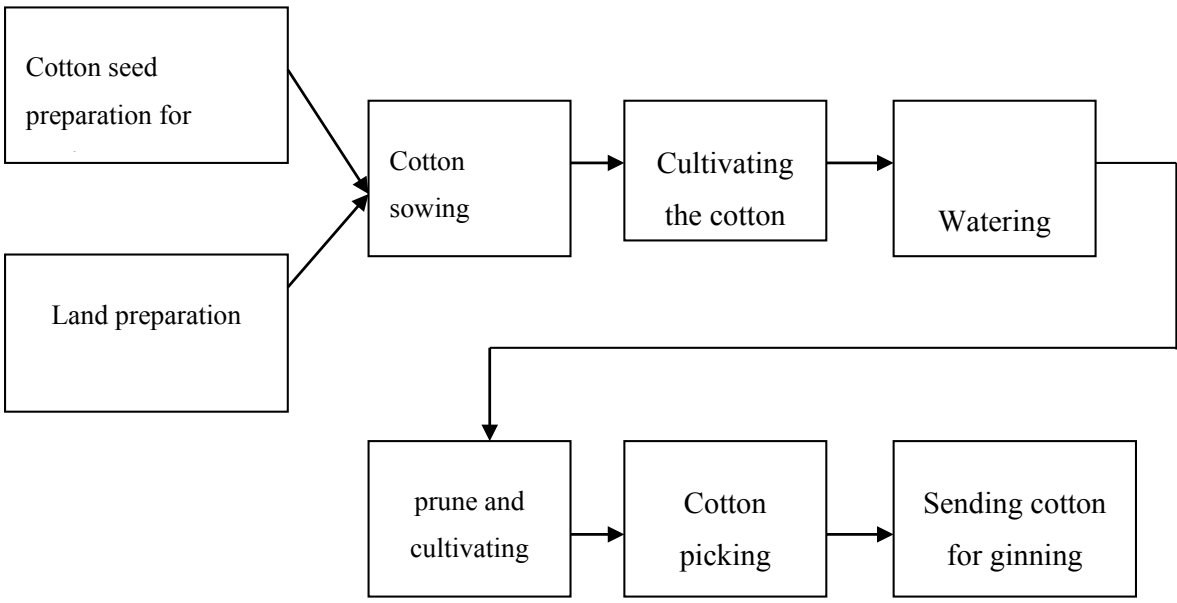

Figure 2: Activity process for the product to be ready.

2. One more opportunity to reduce the cost sum at cotton growing subjects is to reduce fund capacity of these products. Production of fixed assets (machinery and tractors, buildings, equipment and etc.) participate, and transform a portion of their value to the product in the form of depreciation. As production improved, the volume and the amount of fixed assets increase. This, in its turn it will reduce the amount of costs spent to a single unit of product. As a result, one of the key elements to reduce the cost of the product is to lower the stock capacity.

In cotton production, production, maintenance and management of costs also play an important role. These costs include:

1. The salaries ancillary production staff.

2. Service staff salaries.

3. Administrative staff salaries.

4. The economic costs of state-owned buildings and equipment.

5. Water supply facilities and equipment.

6. Business trips costs.

7. The repair costs.

These costs are not directly proportional to the volume of production costs, that is, with the increase in the volume of production the product is not increased, so there is a need to reduce these costs.
3. Another factor affecting to the cost decrease of goods is scientific and technical progress. At cotton producing farms, implementing scientific and technical innovations are very effective. This must involve all the staff in the preparation of raw cotton. The personnel who introduced news and created a certain degree of economic efficiency should be stimulated in every necessary way. Only additional reward leads to movement of the technical activity of personnel. Scientific and technical progress leads to decreasing of cost.

One of the main directions to lower the cost and increasing efficiency is high level of qualification of all personnel and specialists who take part in cotton growing. It is necessary to improve skills and qualification of all specialists constantly and control their knowledge (Figure 3).

But a great part of the arable and row-crop tractors, agricultural machineries were antiquated and outdated, they don't meet requirements of modern standards. There are some problems in material interests of cotton producer. The farmers haven't enough means for application of new techniques and technologies for their farms. All these conditions influence negatively to the development of cotton growing.

The localization of land cultivation is becoming topical worldwide. But the farmers are always complaining about resource shortage. Meanwhile they can decrease the costs of fuel, plant and equipment expenditure by means of reducing the cultivation of soil. It should 


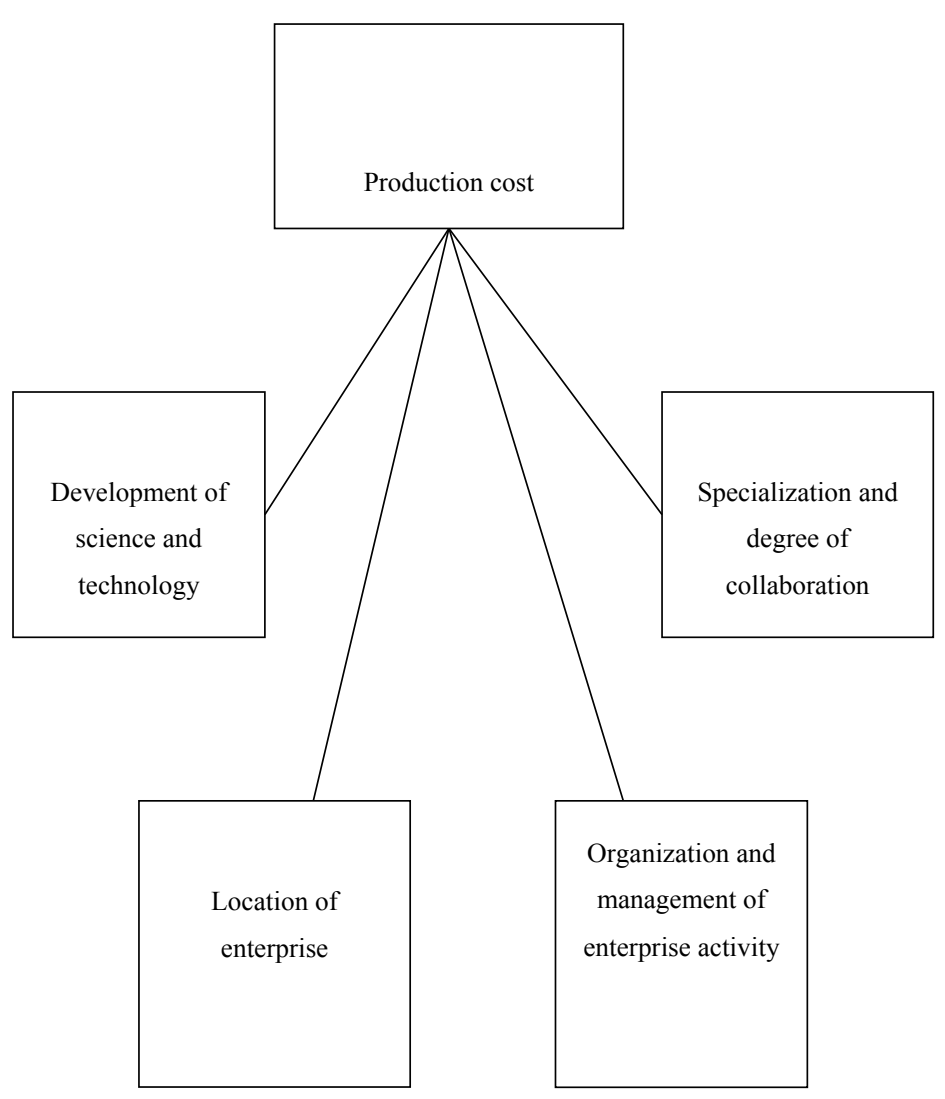

Figure 3: Sources of cost decrease.

be developed proper agricultural methods and their application mechanisms.

Efficient use of resources and the application of resource saving technologies in cotton growing promote economic efficiency according to the market requirements.

We have developed following suggestions on sectoral specificities by application of resource saving technology in cotton growing of our country.

\section{Social specificities of cotton growing sector}

- Consideration of raw cotton grown in our country as a national wealth and effective use of them.

- Guaranteeing of stabile development of cotton growing sector and application of resource saving technologies in this branch.

- Along with development of cotton sector preservation of environment etc.

All these above mentioned specificities will favor the development of economic efficiency of cotton growing, increase the material interests of the sector workers and also preserve the environment.

\section{Economical specificities of cotton growing sector are following}

- Resource period spent on cotton growing is longer than it is in industry i.e. for raw cotton we spent one year but much less for industrial goods.
- The resource cost in cotton growing will be estimated in one year, in industry it last a month or less.

- Discrepancy between given costs and real costs.

- Erratic prices of material resources expanded in cotton growing.

- Inadequacy of competitive environment in resource supply system of cotton growing.

- Seasonal nature of use of manpower in cotton growing sector.

- Labor intensiveness of cotton growing and constant management by economical means;

- Multistage treatment of raw cotton before it becomes a final product.

- Lack of satisfaction of customer demand with intermediate products for cotton producer (vegetables, grain, livestock products can be consumed without any processing) etc.

\section{Financial specificities of cotton growing sector}

- Unstable financial resource of the farmers.

- Results of financial resources spending for cotton growing will be received at the end of the year which increases the financial risk;

- Limited preferential credit by government for cotton producer.

- Default on execution of contractual obligations by the companies serving cotton growing sector.

- Deficiency of financial resource for innovation of cotton farms. 
Citation: Alojonovich RR (2017) The Main Directions of Cost Reduction and Increasing Effectiveness in Cotton Production. Agrotechnology 6: 168. doi: $10.4172 / 2168-9881.1000168$

Page 4 of 4

Specificities of cotton growing sector show the variety of factors influencing on branch efficiency and their importance in economical effectiveness is great. For the world market the cotton is valuable for its fiber and quality. The productivity of raw cotton grown in different natural and climatic conditions is different as well. Raw cotton is grown in different quality of locality i.e. in lowland, middle land and in the hills. That is why branch specificities should be taken into account in order to form efficient system of development of cotton sector which will increase the cotton fertility and its quality [6-13].

\section{Conclusion}

In cost decreasing improving the organization of production and reducing production cost is also greatly affected. Improving labour conditions, organizing work place and serving to the work place and others will impact greatly on the cost of the product.

In cotton growing all impacting indicators of labor productivity should be analyzed deeper, created action plans to improve the effectiveness and implemented.

\section{References}

1. Abduganiev AA (2003) Economy of agriculture. P: 133.

2. Karimov IA (2009) World financial and economic crisis, ways and measures on its overcoming in the conditions of Uzbekistan. T: Uzbekistan 4-5.
3. Hakimov R, Otaqulov M, Yusupov E, Yusupov M (2003) Economy of agricultural complex. TSUE p: 17.

4. Abdiev AC (1999) Improvement of economic relations between economics players in system of cotton producing complex. Dissertation for a degree of Master of Science in Economics. Tashkent. Research and development center of Uzbekistan. Pp: 12-13.

5. Shermatov OA (2006) The ways of development and increasing of economic efficiency of cotton producing in a situation of relaxation of economy". Dissertation for a degree of Master of Science in Economics. Tashkent. Pp: 10-11.

6. Abdullaev Y (1997) Basics of market economy. Tashkent. Mehnat.

7. Husanov RA, Dadaboev YT, Dadaboev DY (2003) Economy of agricultural complex. Tashkent. Uzbekistan. P: 470.

8. Abduganiev A (2004) Rural economy- Tashkent Literature Fund of Writers Union of Uzbekistan.

9. Husanov RA (1993) The main point of new technology in raw cotton growing - Tashkent, Mehnat.

10. Ulmasov A, Vahobov A (2006) Theory of economics - Tashkent. P: 34.

11. Zokirov O, Pardaev A (2004) Rural economy. Tashkent, UAJBNT.

12. Rajabov I (2006) Balance of the market of agricultural resources in a situation of relaxation of economy. Doctoral dissertation in Economics. Tashkent.

13. Abdullaev RB (2001) Development of export potential of agrarian sector in a situation of relaxation of economy in Uzbekistan (by example of cotton fiber export). Doctoral dissertation in Economics. Tashkent. Research-anddevelopment center of Uzbekistan. P: 307. 